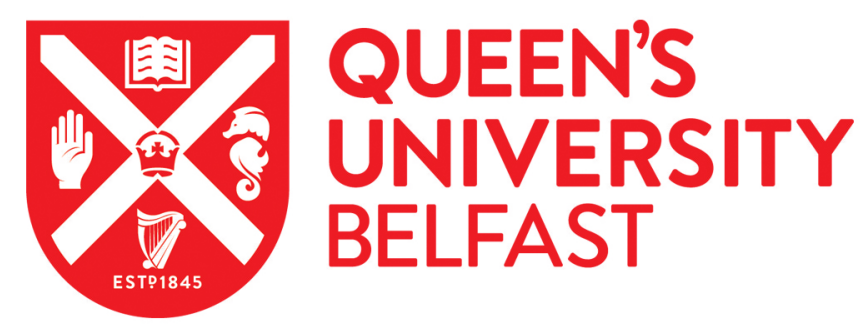

\title{
Using functional responses to quantify notonectid predatory impacts across increasingly complex environments
}

\author{
Cuthbert, R. N., Dalu, T., Wasserman, R. J., Callaghan, A., Weyl, O. L. F., \& Dick, J. T. A. (2018). Using \\ functional responses to quantify notonectid predatory impacts across increasingly complex environments. Acta \\ Oecologica. https://doi.org/10.1016/j.actao.2018.11.004
}

Published in:
Acta Oecologica

Document Version:

Peer reviewed version

Queen's University Belfast - Research Portal:

Link to publication record in Queen's University Belfast Research Portal

\section{Publisher rights}

Copyright 2018 Elsevier

This manuscript is distributed under a Creative Commons Attribution-NonCommercial-NoDerivs License

(https://creativecommons.org/licenses/by-nc-nd/4.0/), which permits distribution and reproduction for non-commercial purposes, provided the author and source are cited.

\section{General rights}

Copyright for the publications made accessible via the Queen's University Belfast Research Portal is retained by the author(s) and / or other copyright owners and it is a condition of accessing these publications that users recognise and abide by the legal requirements associated with these rights.

Take down policy

The Research Portal is Queen's institutional repository that provides access to Queen's research output. Every effort has been made to ensure that content in the Research Portal does not infringe any person's rights, or applicable UK laws. If you discover content in the Research Portal that you believe breaches copyright or violates any law, please contact openaccess@qub.ac.uk. 


\section{Short Communication}

\section{Using functional responses to quantify notonectid predatory impacts across increasingly complex environments}

Ross N. Cuthbert ${ }^{\mathrm{a}, \mathrm{b}, \mathrm{c}, *}$, Tatenda Dalu ${ }^{\mathrm{d}, \mathrm{e}}$, Ryan J. Wasserman ${ }^{\mathrm{e}, \mathrm{f}}$, Amanda Callaghan ${ }^{\mathrm{c}}$, Olaf L.F. Weyl ${ }^{\mathrm{b}}$, Jaimie T.A. Dick ${ }^{\mathrm{a}}$

a Institute for Global Food Security, School of Biological Sciences, Queen's University Belfast, Medical Biology Centre, Belfast BT9 7BL, Northern Ireland

${ }^{\mathrm{b}}$ DST/NRF Research Chair in Inland Fisheries and Freshwater Ecology, South African Institute for Aquatic Biodiversity (SAIAB), Grahamstown 6140, South Africa

${ }^{\mathrm{c}}$ Ecology and Evolutionary Biology, School of Biological Sciences, University of Reading, Harborne Building, Reading RG6 6AS, England

${ }^{d}$ Ecology and Resource Management, University of Venda, Thohoyandou 0950, Limpopo, South Africa

${ }^{e}$ South African Institute for Aquatic Biodiversity (SAIAB), Grahamstown 6140, South Africa ${ }^{f}$ Biological Sciences and Biotechnology, Botswana International University of Science and Technology, P. Bag 16, Palapye, Botswana

${ }^{*}$ Corresponding author: Ross N. Cuthbert (rcuthbert03@qub.ac.uk) 


\begin{abstract}
Predation is a key biotic interaction that influences both the structure and functioning of ecosystems, and is relevant in the biological control context. Levels of habitat complexity in aquatic ecosystems are highly variable and can profoundly affect predator-prey interactions through the presence of prey refugia, which can in turn reduce predatory efficacy. Here, we use functional responses (FRs, resource use under different resource densities) to quantify the predatory impact of the notonectid Anisops debilis towards larvae of the mosquito Culex pipiens under a habitat complexity gradient. Anisops debilis displayed a potentially population-destabilising Type II FR towards larval C. pipiens prey across the habitat complexity gradient. Attack rates were highest in simple environments, however handling times were not significantly affected by habitat complexity. Maximum feeding rates of $A$. debilis towards $C$. pipiens larvae were thus robust to habitat complexity variations. Our results demonstrate the substantial predatory impacts of notonectids towards larval mosquito prey irrespective of habitat complexities, which may assist in the biological control of pests and vectors in aquatic systems.
\end{abstract}

\title{
Keywords
}

predator-prey; biological control; functional response; habitat complexity; Anisops debilis; Culex pipiens 


\section{Introduction}

Biotic interactions such as predation play a central role in ecosystem structuring and functioning (Brooks and Dodson, 1965; Carpenter et al., 1975; Wasserman et al., 2013). Regulatory impacts of natural enemies towards pests, vectors and invasive species are in turn reliant on processes such as predation (Solomon, 1949; O'Neil, 1990; Golding et al., 2015). As environmental context-dependencies can have a significant influence on predatory impacts (e.g. South et al., 2017), considering predator-prey interaction strengths across these contexts is important for robust impact quantifications towards target prey (e.g. Cuthbert et al., 2018a, b, c). Functional responses have been central to the development of consumerresource (e.g. predator-prey) theories (Solomon, 1949; Holling, 1959), and have been regularly applied in examining environmental context-dependencies of biotic interaction strengths (e.g. Wasserman et al., 2018a; Cuthbert et al., 2018a, b, c). Three FR forms have been broadly described: a linear Type I, hyperbolic Type II and sigmoidal Type III (Holling, 1959), with each pertaining to different consumer-resource interaction outcomes. For instance, Type II FRs are considered to be destabilising to populations under certain conditions due to high resource (e.g. prey) acquisition at low prey densities by predators (Dick et al., 2014). Thus, in the context of biological control, such destabilising FRs can elicit eradications of target species.

Mosquitoes comprise an important trophic stage in many ecosystems, and biotic interactions strengths towards their larvae by predators are known to affect overall mosquito species distributions (Golding et al., 2015). Indeed, mosquitoes colonise a vast range of natural and artificial aquatic environments, including within urban areas (Townroe and Callaghan, 2014). The physical structure of these habitats is inherently varied, with features such as submerged plants often constituting the main components of habitat complexity in aquatic environments (Tokeshi and Arakaki, 2012). Such complexity can modulate the 
interaction strengths between mosquitoes and their predators (e.g. Cuthbert et al., 2018b), which in turn could result in the emergence of reduced predatory success due to physical refugia of prey (e.g. Alexander et al., 2013), and therefore has implications for vector population control.

Culex pipiens complex mosquitoes are competent vectors of diseases such as West Nile Virus (WNV) (Fonseca et al., 2004) and exhibit particularly marked ecological plasticity with respect to habitat selection, colonising a range of habitats across rural-urban gradients (Townroe and Callaghan, 2014). Given that these habitats are highly varied in terms of their physical structuring, understanding the implications of habitat complexity for the predatory impact of natural enemies of mosquitoes is of great importance. Notonectids are voracious, carnivorous insects, and can play a key role in the structuring of communities (e.g. Blaustein, 1998; Wasserman et al., 2016, 2018b), including within transient, ephemeral aquatic systems where mosquitoes frequently proliferate. Indeed, notonectids have been shown to occupy the highest trophic level in ephemeral aquatic ecosystems (e.g. Dalu et al., 2016). Although notonectid predatory efficacy towards mosquito larvae has been described (e.g. Fischer et al., 2013; Silberbush et al., 2014), effects of habitat complexity on these biotic interactions have not been fully constrained. Therefore, here we use a comparative, phenomenological FR approach (e.g. Dick et al., 2014; Wasserman et al., 2016; Cuthbert et al., 2018a, b, c) to decipher the effects of habitat complexity on the predatory impact of the notonectid Anisops debilis Gersaeker 1873 towards larvae of the mosquito complex C. pipiens.

\section{Materials and Methods}

Adult $A$. debilis (6.7 - 7.1 mm body length) were collected from an impounded stream in Grahamstown, Eastern Cape, South Africa (33 $\left.{ }^{\circ} 19^{\prime} 00.1^{\prime \prime} \mathrm{S} 26^{\circ} 31^{\prime} 21.2^{\prime \prime} \mathrm{E}\right)$ during the $2017-2018$ austral summer by trawling a kick net through the water column. 
Notonectids were transported in source water to a controlled environment (CE) room at Rhodes University, Grahamstown and maintained at $25 \pm 1{ }^{\circ} \mathrm{C}$ under a 14:10 light:dark photoperiod. The prey, larvae of the $C$. pipiens mosquito complex, originated from egg rafts sampled from artificial container-style habitats situated around the Rhodes University campus. Larvae were reared to the desired size class (see below) in the CE room on a diet of crushed rabbit food pellets (Agricol, Port Elizabeth). Notonectids were housed in continuously aerated aquaria with $25 \mathrm{~L}$ dechlorinated tap water for six days prior to experimentation, and fed ad libitum on larvae of the mosquito C. pipiens. Excellent survivability of notonectids ( $>95 \%$ ) was observed during housing (Cuthbert pers. obs.). On the seventh day, notonectids were separately starved in glass experimental arenas of $5.6 \mathrm{~cm}$ diameter, containing $80 \mathrm{~mL}$ dechlorinated tap water from a continuously aerated source.

We employed a ' $3 \times 7$ ' experimental design with respect to 'habitat complexity' and 'prey supply'. We used stalks of the bulrush Schoenoplectus brachyceras $(4-6 \mathrm{~mm}$ diameter), collected from the notonectid sampling site, to generate three levels of habitat complexity (i.e. low, medium, high). Low complexity arenas held zero stalks, medium complexity arenas contained two stalks and high complexity arenas had four stalks, arranged in a uniform array (c. Wasserman et al. 2016), broadly representing the range of habitat complexities encountered at the notonectid collection site (Cuthbert pers. obs.). Culex pipiens larvae (2.4 - $3.2 \mathrm{~mm}$ length incl. respiratory siphon) were supplied at seven densities for each complexity level $(2,4,6,8,16,32,64 ; n=4$ per experimental group) in glass $80 \mathrm{~mL}$ experimental arenas of $5.6 \mathrm{~cm}$ diameter holding dechlorinated tap water from a continuously aerated source, and allowed to settle for $2 \mathrm{~h}$. Individual notonectid predators were then carefully transferred to arenas containing the allocated prey supply and complexity treatment and allowed to feed for $1 \mathrm{~h}$ during light conditions, before being removed. Then, remaining 
live larval mosquito prey were counted. Controls consisted of a replicate at each prey supply and complexity level in the absence of notonectid predators.

Statistical analyses were conducted in R v.3.4.2 (R Core Team, 2017). Raw consumption was analysed using generalised linear models assuming a Poisson family with respect to the complexity and prey supply treatments. Non-significant terms in the model were removed stepwise (Crawley, 2007). Tukey's comparisons were used post hoc using the package 'lsmeans' (Lenth, 2016). The present study applies FR modelling to address the phenomenological implications of habitat complexity variabilities for predator-prey interactions. That is, our experiment is comparative and does not seek to offer mechanistic insights into predator behaviour (see Jeschke et al., 2002; Dick et al., 2014). Functional responses were thus modelled using the 'frair' package (Pritchard et al., 2017). Functional response types were inferred through the use of logistic regression of the proportion of prey consumed as a function of the prey density supplied, wherein a Type II FR is characterised by a significantly negative linear coefficient (Juliano, 2001). The Rogers' random predator equation was fit as prey were not replaced as they were consumed:

$$
N_{e}=N_{0}\left(1-\exp \left(a\left(N_{e} h-T\right)\right)\right)
$$

Eqn. 1.

where $N_{e}$ is the number of prey eaten, $N_{0}$ is the initial density of prey, $a$ is the attack rate, $h$ is the handling time and $T$ is the total experimental period. We fit the Lambert $\mathrm{W}$ function to further enable FR model fitting (Bolker, 2008). We then bootstrapped $(n=2000)$ FRs to infer $95 \%$ confidence intervals (CIs) using original maximum likelihood estimations (MLEs) (e.g. Wasserman et al., 2016). Overall differences in attack rate and handling time parameters were derived using the difference method outlined in Juliano (2001). We applied Bonferroni 
corrections for multiple comparisons between the three habitat complexity levels (i.e. critical $p=0.017)$

\section{Results}

All 396 mosquito prey survived in controls, and so prey deaths were attributed to predation by notonectids, which we also directly observed. Raw consumption was significantly affected by habitat complexity $\left(\chi^{2}=11.900, d f=2, p=0.003\right)$. Consumption was significantly greater at the low compared to medium $(z=2.454, p=0.04)$, and low compared to high $(z=3.280, p=0.003)$, complexity treatments. Raw consumption did not vary significantly between the medium and high complexities $(z=0.838, p=0.68)$. Consumption was significantly higher under greater prey supplies $\left(\chi^{2}=336.660, d f=6, p<\right.$ 0.001). There was no significant interaction between habitat complexity and prey supply $\left(\chi^{2}=\right.$ $5.520, d f=12, p=0.94)$.

Type II FRs were found irrespective of habitat complexity treatments, and evidenced by significantly negative first order terms (Table 1). Functional response magnitudes trended towards being highest at the low complexity treatment (Figure 1), driven by higher attack rates (initial FR slope), marginally lower handling times and thus higher maximum feeding rates $(1 / h$; FR asymptote) (Table 1$)$. Significantly greater attack rates were found in the low compared to medium complexity treatment $(\mathrm{z}=2.585, p=0.01)$, and in the low compared to high complexity treatment overall $(z=2.592, p=0.01)$. Attack rates did not vary significantly between the medium and high complexity treatments $(z=0.102, p=0.92)$. However, significant differences in handling times were not detected between any levels of habitat complexity (low - medium, $z=0.546, p=0.59$; low - high, $z=1.405, p=0.16$; medium - high, $z=0.836, p=0.40)$.

\section{Discussion}


Our results demonstrate consistency of Type II FRs by A. debilis towards larvae of the disease vector complex C. pipiens irrespective of habitat complexities. Thus, destabilising predatory impacts of this notonectid are unaffected by the presence of habitat complexity, with Type II FRs characteristically associable with localised prey extinctions under certain conditions due to high resource (e.g. prey) utilisation at low prey densities (Dick et al., 2014). These results corroborate with the recorded ability of notonectids to exert marked impacts upon the biotic structure of communities within varied aquatic ecosystems (e.g. Blaustein, 1998; Wasserman et al., 2016, 2018b). Indeed, Type II FR forms have been previously recorded with congenerics of A. debilis (e.g. Zuhurah and Lester, 2011). However, as FRs only examine per capita effects of consumers, further investigation of predator populationlevel responses (e.g. abundance or fecundity) would be of value in constraining comprehensive ecological impacts (see Dick et al., 2017; Cuthbert et al., 2018c).

As attack rates of $A$. debilis were highest under low complexities, destabilising predatory impacts at low prey densities can be deemed more profound in simplified habitats. However, as handling times were similar across habitat complexities, maximum feeding rates were relatively unaffected by the habitat complexity gradient. Thus, as maximum feeding rates have proven robust in derivations of consumer-resource impact (Dick et al., 2017), the overall predatory impact of $A$. debilis towards mosquito prey can in turn be deemed similar across habitat complexities here. Previous research has shown A. debilis to be tolerant to ranging environmental conditions, however predatory efficiency has been shown to be affected by salinity gradients (Silberbush et al., 2014). Furthermore, other effective predatory biological control agents of mosquitoes, such as cyclopoid copepods, have shown similar responses to habitat complexity as those demonstrated in the present study (e.g. Cuthbert et al., 2018b). Although implications of habitat complexity are constrained here, biotic contexts such as alternative prey may induce further implications for predator-prey interactions 
through processes such as prey preferences and switching (e.g. Cuthbert et al., 2018d). Alternative prey has been shown to influence predatory impacts on target species, although many studies have demonstrated that notonectid impacts on larval mosquito prey remain high in the presence of certain alternative prey (e.g. Saha et al., 2010; Fischer et al., 2013; Saha et al., 2014). In particular, Saha et al. $(2010,2014)$ demonstrated that a congeneric Anisops preferentially consumed mosquitoes over other prey types. Furthermore, the generalist feeding traits of notonectids are advantageous as this group can forage on alternative prey when mosquito abundances are low, potentially sustaining population levels.

Given the range of forms of aquatic habitats which mosquitoes colonise across ruralurban gradients, our results indicate that certain natural enemies of mosquitoes, such as $A$. debilis, may retain strong predatory efficacy irrespective of habitat variations. Aerial adult mosquito life-history stages ensure efficient colonisation of aquatic systems across the landscape. Unlike other aquatic mosquito predators such as copepods (Cuthbert et al., 2018a, b, c), notonectids can efficiently and naturally colonise aquatic habitats given that they too are capable of aerial dispersal (McCauley and Row, 2010). Thus, encouraging the proliferation of such natural enemies may assist with population-level control of vectoriallyimportant mosquitoes across a broad range of aquatic systems with different environmental characteristics. Further research should seek to examine the impacts of additional environmental contexts on biotic processes, particularly in terms of their effects on the efficacy of natural enemies of pests, vectors and invasive species.

\section{Acknowledgements}

This study forms part of a PhD studentship funded by the Department for the Economy, Northern Ireland. We extend gratitude to Rhodes University for the provision of laboratory facilities. We also thank Martin Villet and Terence Bellingan for assistance with species 
identifications. We acknowledge use of infrastructure and equipment provided by the SAIAB Research Platform and the funding channelled through the NRF-SAIAB Institutional Support system. This study was partially funded by the National Research Foundation - South African Research Chairs Initiative of the Department of Science and Technology (Inland Fisheries and Freshwater Ecology, Grant No. 110507).

\section{Author contributions}

Conceived and designed the experiments: R.C., T.D., R.W., O.W., J.D. Performed the experiments: R.C., T.D. Analysed the data: R.C. Contributed materials and analysis tools: R.C., T.D., A.C., O.W. Wrote the first draft of paper: R.C. Prepared revised versions: R.C., T.D., R.W., A.C., O.W., J.D.

\section{References}

Alexander, M.E., Dick, J.T.A., O’Connor, N.E., 2013. Trait- mediated indirect interactions in a marine intertidal system as quantified by functional responses. Oikos 122, 15211531.

Blaustein, L., 1998. Influence of the predatory backswimmer, Notonecta maculata, on invertebrate community structure. Ecol. Entomol. 23, 246-252.

Bolker, B.M., 2008. emdbook: Ecological Models and Data in R. Princeton Univ. Press, Princeton.

Brooks, J.L., Dodson, S.I., 1965. Predation, body size, and composition of plankton. Science $150,28-35$.

Carpenter, S.R., Kitchell, J.F., Hodgson, J.R., 1985. Cascading trophic interactions and lake productivity. BioScience 35, 634-639.

Crawley, M.J., 2007. The R Book. John Wiley, Chichester. 
Cuthbert, R.N., Callaghan, A., Dick, J.T.A., 2018a. Dye another day: the predatory impact of cyclopoid copepods on larval mosquito Culex pipiens is unaffected by dyed environments. J. Vector Ecol. in press.

Cuthbert, R.N., Callaghan, A., Dick, J.T.A., 2018b. Interspecific variation, habitat complexity and ovipositional responses modulate the efficacy of cyclopoid copepods in disease vector control. Biol. Control 121: 80-87.

Cuthbert, R.N., Dick, J.T.A., Callaghan, A., Dickey, J.W.E., 2018c. Biological control agent selection under environmental change using functional responses, abundances and fecundities; the Relative Control Potential (RCP) metric. Biol. Control 121, 50-57.

Cuthbert, R.N., Dickey, J.W.E., McMorrow, C., Laverty, C., Dick, J.T.A., 2018d. Resistance is futile: lack of predator switching and a preference for native prey predict the success of an invasive prey species. R. Soc. Open Sci. 5, 180339.

Dalu, T., Weyl, O.L.F., Froneman, P.W., Wasserman, R.J., 2016. Trophic interactions in an austral temperate ephemeral pond inferred using stable isotope analysis. Hydrobiologia 768, 81-94.

Dick, J.T.A., Alexander, M.E., Jeschke, J.M., Ricciardi, A., MacIsaac, H.J., Robinson, T.B., Kumschick, S., Weyl, O.L.F., Dunn, A.M., Hatcher, M.J., Paterson, R.J., Farnsworth, K.D., Richardson, D.M., 2014. Advancing impact prediction and hypothesis testing in invasion ecology using a comparative functional response approach. Biol. Invasions $16,735-753$.

Dick, J.T.A., Laverty, C., Lennon, J.J., Barrios-O'Neill, D., Mensink, P.J., Britton, R., Médoc, V., Boets, P., Alexander, M.E., Taylor, N.G., Dunn, A.M., Hatcher, M.J., Rosewarne, P.J., Crookes, S., MacIsaac, H.J., Xu, M., Ricciardi, A., Wasserman, R.J., Ellender, B.R., Weyl, O.L.F., Lucy, F.E., Banks, P.B., Dodd, J.A., MacNeil, C., Penk, 
M.R., Aldridge, D.C., Caffrey, J.M., 2017. Invader Relative Impact Potential: a new metric to understand and predict the ecological impacts of existing, emerging and future invasive alien species. J. Appl. Ecol. 5,: 1259-1267.

Fischer, S., Zanotti, G., Castro, A., Quiroga, L., Vargas, D.V., 2013. Effect of habitat complexity on the predation of Buenoa fuscipennis (Heteroptera: Notonectidae) on mosquito immature stages and alternative prey. J. Vector Ecol. 38, 215-223.

Fonseca, D.M., Keyghobadi, N., Malcolm, C.A., Mehmet, C., Schaffner, F., Mogi, M., Fleischer, R.C., Wilkerson, R.C., 2004. Emerging vectors in the Culex pipiens complex. Science 303, 1535-1538.

Golding, N., Nunn, M.A., Purse, B.V., 2015. Identifying biotic interactions which drive the spatial distribution of a mosquito community. Parasit. Vectors 8, 367.

Holling, C.S., 1959. Some characteristics of simple types of predation and parasitism. Can. Entomol. 91, 385-398.

Jeschke, J., Kopp, M., Tollrian, R., 2002. Predator functional responses: discriminating between handling and digesting prey. Ecol. Monograph 72, 95-112.

Juliano, S.A., 2001. Nonlinear curve fitting: predation and functional response curves, in: Scheiner, S.M., Gurevitch, J. (Eds.), Design and Analysis of Ecological Experiments. Oxford University Press, Oxford, pp. 178-196.

Lenth, R.V., 2016. Least-Squares Means: The R Package 1smeans. J. Stat. Softw. 69, 1-33

McCauley, S.J. Rowe, L., 2010. Notonecta exhibit threat-senstive, predator-induced dispersal. Biol. Lett. 6, 448-452.

Ohtsuka, S., Huys, R., 2001. Sexual dimorphism in calanoid copepods: morphology and function. Hydrobiologia 453/454, 441-466. 
Pritchard, D.W., Paterson, R., Bovy, H.C., Barrios-O’Neill, D., 2017. Frair: an R package for fitting and comparing consumer functional responses. Methods Ecol. Evol. 8, 15281534.

R Core Team, 2017. R: A language and environment for statistical computing. R Foundation for Statistical Computing, Vienna.

Saha, N., Aditya, G., Saha, G.K., Hampton, S.E., 2010. Opportunistic foraging by heteropteran mosquito predators. Aquat. Ecol. 44, 167-176.

Saha, N., Aditya, G., Saha, G.K., 2014. Prey preferences of aquatic insects: potential implications for the regulation of wetland mosquitoes. Med. Vet. Entomol. 28, 1-9.

Silberbush, A., Tsurim, I., Margalith, Y., Blaustein, L., 2014. Interactive effects of salinity and a predator on mosquito oviposition and larval performance. Popul. Ecol. 175, $565-575$.

Solomon, M.E., 1949. The natural control of animal populations. J. Anim. Ecol. 18, 1-35.

South, J., Dick, J.T.A., McCard, M., Barrios-O'Neill, D., Anton, A., 2017. Predicting predatory impact of juvenile invasive lionfish (Pterois volitans) on a crustacean prey using functional response analysis: effects of temperature, habitat complexity and light regimes. Environ. Biol. Fish. 100, 1155-1165.

Tokeshi, M, Arakaki, S., 2012. Habitat complexity in aquatic systems: fractals and beyond. Hydrobiologia 685, 27-47.

Townroe, S. Callaghan., A., 2014. British container breeding mosquitoes: The impact of urbanisation and climate change on community composition and phenology. PLoS ONE 9, e95325. 
Wasserman, R.J., Margaux, N., Avery, T.S., Froneman, P.W., 2013. Trophic level stabilityinducing effects of predaceous early juvenile fish in an estuarine mesocosm study. PLos ONE 8, e61019.

Wasserman, R.J., Alexander, M.E., Weyl, O.L.F., Barrios-O’Neill, D., Froneman, P.W., Dalu, T., 2016. Emergent effects of structural complexity and temperature on predator-prey interactions. Ecosphere 7, e01239.

Wasserman, R.J., Cuthbert, R.N., Alexander, M.E., Dalu, T., 2018a. Shifting interaction strength between estuarine mysid species across a temperature gradient. Mar. Environ. Res. 140, 390-393.

Wasserman, R.J., Weston, M., Weyl, O.L.F., Froneman, P.W., Welch, R.J., Vink, T.J.F., Dalu, T., 2018b. Sacrificial males: the potential role of copulation and predation in contributing to copepod sex-skewed ratios. Oikos 127, 970-980.

Zuhurah, W.F., Lester, P.J., 2011. Are exotic invaders less susceptible to native predators? A test using native and exotic mosquito species in New Zealand. Popul. Ecol. 53, 307317. 
Table 1. First order terms with associated probabilities derived from logistic regression of proportional prey consumption as a function of prey supply across all habitat complexity levels, alongside original attack rate and handling time parameter estimates with associated probabilities.

\begin{tabular}{|l|l|l|l|}
\hline Habitat complexity & First order term, $p$ & Attack rate, $p$ & Handling time, $p$ \\
\hline Low & $-0.036,<0.001$ & $2.490,<0.001$ & $0.040,<0.001$ \\
\hline Medium & $-0.030,<0.001$ & $1.387,<0.001$ & $0.044,<0.001$ \\
\hline High & $-0.028,<0.001$ & $1.356,<0.001$ & $0.052,<0.001$ \\
\hline
\end{tabular}


Figure 1. Type II functional responses of Anisops debilis towards Culex pipiens across low (a, solid line), medium (b, dashed line) and high (c, dotted line) habitat complexities. Shaded areas represent bootstrapped $95 \%$ confidence intervals $(n=2000)$ and open circles represent raw residual points ( $n=4$ replicates per density). 